\title{
Investigação da Deterioração por Fungos Filamentosos em Empanados Congelados de Frango
}

\author{
Évelin Francine Wigmann (I), Raquel Carine Jahn (I), Catia Daiane \\ Scherer (I), María de Jesús Alcano (I), Fernanda Saccomori (I), \\ Marina Venturini Copetti (I) \\ (I) UFSM - UNIVERSIDADE FEDERAL DE SANTA MARIA (Av. Roraima, $n^{\circ} 1000$ - Bairro \\ Camobi - Santa Maria)
}

\section{Resumo}

A produção de empanados congelados de frango pela indústria de alimentos surgiu da demanda dos consumidores por produtos de fácil elaboração pela redução do tempo disponível para seu preparo. Esta classe de produtos pré-prontos e congelados permite uma armazenagem por longos períodos, nos quais poderão haver situações de abuso de temperatura permitindo sua deterioração por fungos filamentosos psicrófilos, sobretudo Penicillium glabrum e Penicillium polonicum. Segundo informações da indústria, isso representa perdas de produção anuais de 1 à 1,5\%. Logo, o objetivo deste estudo foi analisar micologicamente as matérias-primas, bem como os empanados congelados de frango e o ar ambiente em diferentes etapas de seu processamento a fim de investigar a origem da contaminação fúngica. Foram analisados um total de 110 amostras, entre elas: farinhas, condimentos, produto após adição de cada farinha, após fritura, após cozimento e produto final já embalado. Foram pesados 10 gramas de cada amostra adicionando $90 \mathrm{ml}$ de água peptonada a $0,1 \%$ e o material foi homogeneizado durante 1 minuto em 'Stomacher', com inoculação em Ágar Batata com cloranfenicol e incubação à $25^{\circ} \mathrm{C}$ por 7 dias. Para análise da contaminação do ar ambiental, placas de Petri com Ágar Dicloran Glicerol 18\% foram expostas por 10, 30 e 60 minutos em áreas consideradas de risco para a contaminação fúngica e incubadas nas mesmas condições acima descritas.

\footnotetext{
Referência:

Évelin Francine Wigmann, Raquel Carine Jahn, Catia Daiane Scherer, María de Jesús Alcano, Fernanda Saccomori, Marina Venturini Copetti.Investigação da Deterioração por Fungos Filamentosos em Empanados Congelados de Frango. In: Anais do $12^{\circ}$ Congresso Latinoamericano de Microbiologia e Higiene de Alimentos - MICROAL 2014 [= Blucher Food Science Proceedings, num.1, vol.1]. São Paulo: Editora Blucher, 2014. 
As espécies foram identificadas através da observação de características macroscópicas e microscópicas dos isolados. As amostras de farinha apresentaram contagens entre $10^{1}$ e $10^{4} \mathrm{UFC} / \mathrm{g}$, predominando as espécies P. polonicum, Aspergillus flavus, Aspergillus candidus, Eurotium amstelodami e Penicillium citrinum. As amostras seguintes ao processamento apresentaram uma constante redução nas contagens para $10^{1}$ UFC/g, com predominância de P. polonicum. Já nas 10 amostras analisadas do produto final, apenas uma apresentou contaminação por P. glabrum, espécie também predominante no ar ambiente da fábrica. De acordo com os resultados, foi observada a associação da contaminação do produto final com a presença da espécie no ambiente de processamento dos empanados, provável fonte de contaminação do produto.

Palavras-Chave: Bolores, Fungos psicrófilos, Contaminação Agência de Fomento: $\mathrm{CNPq}$ 